\title{
Metabolic profiling of mussel larvae: effect of handling and culture conditions
}

Tim Young 1

Andrea C. Alfaro 1,*

Phone +64-9-921-9999

Email andrea.alfaro@aut.ac.nz

Silas G. Villas-Bôas 2

1 Faculty of Health and Environmental Sciences, School of Applied Sciences, Institute for Applied Ecology New Zealand, Auckland University of Technology, Private Bag 92006, Auckland, 1142 New Zealand

2 Centre for Microbial Innovation, School of Biological Sciences, The University of Auckland, Auckland, New Zealand

\section{Abstract}

Gas chromatography mass spectroscopy was applied to characterize the metabolic profiles of hatchery-reared mussel (Perna canaliculus) larvae before and after a prolonged handling and water exchange process, and to investigate the effect of culture conditions. A decrease in succinate and an increase in alanine were observed after the water exchange, which indicated alterations in energy production and osmotic balance. However, these variations were subtle and it is unlikely that the water exchange practice had any lasting negative effects on larval physiology and performance. Multivariate pattern recognition tools (hierarchical clustering, principal component analysis and projection to latent squares discriminant analysis) were used to assess metabolite variations in larvae reared in low-density static and high-density flow through systems and to construct a culture condition classification model. Twelve metabolites 
contributed most towards the model, which indicated differences in energy, protein and lipid metabolism. The clear group separations were not represented by observable variations in morphological traits. This suggests that growth performance is metabolically buffered through an adaptive physiological mechanism to provide similar developmental characteristics under these conditions.

\section{Keywords}

Aquaculture

Larval rearing

Hatchery

Metabolomics

Metabolism

Mussels

Perna canaliculus

Guest editors: Elena Mente and Aad Smaal/Eur Aquaculture Development.

\section{Introduction}

Increased hatchery culture of marine molluscs is necessary to reduce the industry's dependence on wild populations for stocking farms, to provide a reliable high-quality source of spat for on-growing, and to meet future global requirements for marine-based food protein in an environmentally sustainable manner. Mussel aquaculture represents one of the fastest growing seafood sectors, but current product supplies are unable to meet market demands. Unfortunately, inconsistent sources of juveniles have hindered industry development (Martell et al. 2013; Carrasco et al. 2014). The vast majority of mussel farms around the world are dependent on wild-caught spat either by collecting juveniles attached to seaweed which has been washed onshore, or by deploying spat-catching ropes within the water column which free-swimming larvae settle on. However, accurate predictions of the location, timing, and size of any spat-fall is practically impossible, since a large number of complex and poorly understood environmental variables need to be accounted for (Wilson 2008). Furthermore, the effect of spat-catching 
on natural population dynamics for many species is unknown. Hatchery production of larvae can provide an alternative supply. While higher production overheads are generally associated with hatchery-reared juveniles compared to wild-caught spat, such expenses can be offset by using ultra-high-density larval rearing practices, seeding ropes with more spat, incorporation of selective breeding programs to achieve higher-value products, and the possibility for growing triploids to enhance meat yields, among others (Kamermans et al. 2013).

Many regions with high mussel production, such as Europe, China and Chile, have not yet invested significantly in the development of mussel hatchery technologies. However, clear global interest is growing among producers and stakeholders (Kamermans et al. 2013; Carrasco et al. 2014). Small-scale hatchery production of larvae for commercial research purposes has recently been conducted with a number of important advances coming from the west coast USA, Canada, South Australia and New Zealand (SARF 2014). These ventures are providing solid working foundations for the up-scaling of production, and highlight the effectiveness of such facilities. For example, in New Zealand, strong government support and highly successful R\&D by two leading aquaculture research organisations (SPATnz and Cawthron Institute) has led to the current development of the world's largest mussel hatchery, which is set to provide industry with substantial quantities of Greenshell ${ }^{\mathrm{TM}}$ mussel (Perna canaliculus) spat (Capson and Guinotte 2014).

As with other bivalves, numerous challenges face the successful larval production of mussels, which include factors associated with broodstock conditioning, gamete quality, larval nutrition, disease (bacterial, viral and parasitic pathogens), water quality, variations in growth, and synchronization of developmental timing (e.g., settlement and metamorphosis). While many advances have been made over the past decade, such as optimized feeding regimes (Ragg et al. 2010), use of probiotics (Kesarcodi-Watson et al. 2012a,b), and identification of larval settlement inducers (Young et al. 2011, 2015a), high mortality events during larval culture and variable spat production yields are commonly experienced for some species. Undoubtedly, there is still much to learn about the fundamental biology and requirements of 
marine bivalves during early development, and considerable scope exists to further optimize and fine-tune the larval rearing conditions.

Metabolic profiling, or metabolomics, is a newly emerging approach for studying biological systems. With foundations in other post-genomic fields, such as transcriptomics (the profiling of expressed genes) and proteomics (the profiling of expressed proteins), metabolomics aims to capture and characterize the profile of small metabolites in cells, tissues and organisms (Villas-Bôas et al. 2007). Metabolites reflect the final products of gene expression, but they are also tightly regulated by external environmental influences and thus more closely represent the phenotype of an organism (Patti et al. 2012). As the molecules of metabolism, differential metabolite profiles can provide important insights into how an organism actually responds metabolically to different situations, such as temperature changes (Dunphy et al. 2015), variations in salinity (Koyama et al. 2015), exposure to poor water quality (Ji et al. 2015), dietary manipulation (Jin et al. 2015), longterm handling stress (Karakach et al. 2009), and super-intensive culture conditions (Schock et al. 2013), among others. Use of metabolomicsbased approaches in aquaculture research is starting to gain tract (reviewed by Alfaro and Young in review; Young and Alfaro in review). However, thus far, only one other early life-stage investigation during hatchery culture of shellfish larvae has been performed (Young et al. 2015b).

We recently used metabolic profiling to identify a suit of candidate biomarkers for assessing mussel ( $P$. canaliculus) larval quality, based on growth variations (Young et al. 2015b). Results demonstrated that the quality of larvae could be modelled using multivariate pattern recognition tools, and provided good evidence that visually different phenotypes within a larval cohort are represented by the composition of the identified metabolites. In the current study, we use metabolic profiling to investigate whether physiological larval traits, which are not morphologically observable, can be distinguished as a result of short-term handling stress during prolonged water exchanges, and when organisms are reared under different culture conditions. The development and incorporation of new methods to assess and monitor the physiological condition of larvae, which cannot be measured with 
currently-used microscopic techniques would be highly valuable for the developing mussel industry.

\section{Methods}

\section{Larval rearing}

Perna canaliculus larvae were reared to 10 days post-fertilisation (veliger stage) under two culture conditions (low density static vs. high density flow through) using standard industry protocols. Gametes were obtained from selectively bred broodstock via thermal shock. Oocytes and sperm were separately pooled from a number of individuals ( $>30$ males and females), then distributed among eight tanks containing $15 \mathrm{~L}$ of $2 \mu \mathrm{m}$ filtered seawater (FSW) at an approximate density of 3500 eggs.mL $\mathrm{mL}^{-1}$ and 50 sperm.egg ${ }^{-1}$. Successful fertilisation was confirmed via microscopy after $1 \mathrm{~h}$ by formation of polar bodies. Zygotes were pooled and equally distributed between two large cylindrical static tanks containing $5000 \mathrm{~L}$ of continuously aerated FSW. After 2 days incubation, embryos had developed into D-stage larvae and the first water exchange was performed. Organisms were filtered through a mesh screen and the bulk of them were placed back into clean $5000 \mathrm{~L}$ tanks containing fresh FSW. A portion of larvae ( $\mathrm{n} \approx 60$ million) were removed from the static culture system and equally distributed among three $150 \mathrm{~L}$ flow through conical tanks containing $100 \mathrm{~L}$ of continuously aerated FSW. Larvae were fed ad libitum (routinely checked via fluorimeter) with a mixed diet of Chaetocerous calcitrans and Isochrisis galbana and reared for a further 8 days under the two different culture regimes. Larval rearing conditions are summarised in Table 1 .

Table 1

Larval rearing parameters used during low-density static and high-density flow through culture

\begin{tabular}{|l|l|l|l|}
\hline Parameter & Incubation & Static system & $\begin{array}{l}\text { Flowthrough } \\
\text { system }\end{array}$ \\
\hline $\begin{array}{l}\text { Water } \\
\text { volume }\end{array}$ & $5000 \mathrm{~L}$ & $5000 \mathrm{~L}$ & $100 \mathrm{~L}$ \\
\hline Density & 60 embryos $\mathrm{mL}^{-1}$ & 20 larvae $\mathrm{mL}^{-1}$ & 200 larvae $\mathrm{mL}^{-1}$ \\
\hline
\end{tabular}




\begin{tabular}{|c|c|c|c|}
\hline Parameter & Incubation & Static system & $\begin{array}{l}\text { Flowthrough } \\
\text { system }\end{array}$ \\
\hline Temperature & $17 \pm 0.5^{\circ} \mathrm{C}$ & $18 \pm 0.5^{\circ} \mathrm{C}$ & $18 \pm 0.5^{\circ} \mathrm{C}$ \\
\hline $\begin{array}{l}\text { Continuous } \\
\text { flowrate }\end{array}$ & $\mathrm{N} / \mathrm{A}$ & N/A & $1000 \mathrm{~mL} \min ^{-1}$ \\
\hline $\begin{array}{l}100 \% \text { water } \\
\text { exchange }\end{array}$ & $\mathrm{N} / \mathrm{A}$ & Every 2 days & Every 2 days \\
\hline $\begin{array}{l}\text { Water } \\
\text { exchange } \\
\text { duration }\end{array}$ & & $90 \mathrm{~min}$ & $10 \mathrm{~min}$ \\
\hline Diet & $\mathrm{N} / \mathrm{A}$ & $\begin{array}{l}\text { C. calcitrans \& } I \text {. } \\
\text { galbana ( } 4: 1 \text { ratio), } \\
\text { batch fed daily with } \\
\text { an increasing } \\
\text { number of cells per } \\
\text { larva to provide ad } \\
\text { libitum feeding } \\
(2000-10,000 \\
\left.\text { cells larva day }{ }^{-1}\right)\end{array}$ & $\begin{array}{l}\text { C. calcitrans \& I. } \\
\text { galbana ( } 4: 1 \\
\text { ratio), } \\
\text { continuously } \\
\text { introduced via } \\
\text { pump to provide } \\
\text { organisms with the } \\
\text { same daily dietary } \\
\text { ration as in the } \\
\text { static system }\end{array}$ \\
\hline
\end{tabular}

\section{Larval sampling}

To test the effects of handling stress, pooled samples of larvae $(n \approx 100,000$ individuals) were taken from each of the $5000 \mathrm{~L}$ tanks at 10 days post-fertilisation, before and after a $100 \%$ water exchange. Draining of the tanks took approximately one and a half hours, during which time; larvae were collected on mesh screens positioned at the outflows. Once finished, larvae were placed back into tanks containing fresh FSW and left to equilibrate for $1 \mathrm{~h}$ before being re-sampled. To sample the larvae, $10 \mathrm{~L}$ of water were taken from the top of the tanks and concentrated on an $80 \mu \mathrm{m}$ mesh screen. Organisms were transferred via pipette into $2 \mathrm{~mL}$ cryovials, excess water was removed, and then samples were immediately snap frozen in liquid nitrogen and transferred to $\mathrm{a}-80{ }^{\circ} \mathrm{C}$ freezer until metabolite extraction. To test the effect of culture conditions, larval samples were also taken from each of the flow through tanks at 10 days post-fertilisation. A water volume of $1250 \mathrm{~mL}$ was filtered through a mesh screen to provide equal numbers of larvae as in the samples obtained from the static system, and similarly processed. The vital stain Neutral Red was used to confirm that only live organisms were included in the larval samples. Following 
the protocol by Young et al. (2015a), ten replicate subsamples (each containing approximately 20 organisms) from every tank were assessed.

\section{Metabolic profiling and data processing}

Metabolic profiling was performed according to established methods (Villas-Bôas et al. 2011). Briefly, metabolites were co-extracted with an internal standard (L-alanine-2,3,3,3-d4) in cold $\mathrm{MeOH}: \mathrm{H}_{2} \mathrm{O}$ and derivatized by methyl chloroformate (MCF) alkylation to convert amino and non-amino organic acids into volatile carbamates and esters. The MCF derivatives were analyzed using a GC-MS system (GC7890 coupled to a MSD5975, Agilent technologies), with a quadrupole mass selective detector (EI) operated at $70 \mathrm{eV}$. The column used for all analyses was a ZB-1701 GC capillary column $(30 \mathrm{~m} \times 250 \mu \mathrm{m}$ id $\times 0.15 \mu \mathrm{m}$ with $5 \mathrm{~m}$ guard column, Phenomenex). The MS was operated in scan mode (start after 6 min; mass range 38-650 a.m.u. at 1.47 scans s $^{-1}$ ). Samples were injected under pulsed splitless mode with the injector temperature at $290{ }^{\circ} \mathrm{C}$. The helium gas flow through the GC column was set at $1 \mathrm{~mL} \mathrm{~min}{ }^{-1}$. The interface temperature was set to $250{ }^{\circ} \mathrm{C}$, and the quadrupole temperature was $200{ }^{\circ} \mathrm{C}$.

Raw spectral data were pre-processed according to Smart et al. (2010), using the R package Metab V1.0 (Aggio et al. 2011) to facilitate highthroughput processing of the data by the Automated Mass Spectral Deconvolution and Identification System (AMDIS). Twenty seven metabolites from different chemical classes were reliably identified by comparing retention times and $\mathrm{m} / \mathrm{z}$ ratios against an in-house library of spectra. Metabolite peak intensities were normalized against the internal standard to compensate for potential technical variations (e.g., variable metabolite recoveries), and the relative metabolite abundances $\left(\sum\right.$ peaks $_{\mathrm{i}-\mathrm{j}} /$ peak $\left._{\mathrm{i}}\right)$ were calculated for each sample. The dataset matrix was converted to a.csv file and the data were standardized (mean centered and unit variance scaled [autoscaled]) before being subjected to a variety of feature selection methods to assess group differences.

\section{Statistical analyses}

SPSS v.22.0 software (SPSS, Chicago, IL, USA) and MetaboAnalyst v.3.0 (a comprehensive web-based analytical pipeline high-throughput 
metabolomics studies [Xia et al. 2015]) were used to analyze data. To investigate the effect of handling stress on the metabolite pool, paired $t$ test statistics and fold-change (FC) values were calculated, where: $\mathrm{FC}=\bar{x} \log _{2}$ post-handled/pre-handled (unstandardized data). To examine whether the culture conditions had an influence on larval metabolic profiles, unpaired $t$ test statistics, FC values, multivariate clustering, and multivariate projection-based techniques were employed. Agglomerative hierarchical cluster analysis (HCA) was initially used as an unbiased method to identify inherent sample groupings, based on the underlying structure of the data. Pearson's correlation and Ward's criterion were selected as the measure of distance and aggregation, respectively. Unsupervised principal components analysis (PCA) was performed to reduce dimensionality, assess the between-sample variation, and investigate natural sample groupings. PCA is a mathematical procedure that aims to capture and extract most of the important information in a high-dimensional data matrix and re-express it in fewer dimensions. In doing so, the data can be more easily visualised, described and analysed. Supervised projection to latent structures discriminant analysis (PLS-DA) was performed to identify metabolites which contributed most towards partitioning of samples between the culture conditions. PLS-DA uses a multivariate regression technique to extract via linear combination of original variables the information that can predict the sample class membership. Leave-one-out cross validation (LOOC) was used to assess the performance of the PLS-DA model. Metabolites contributing most towards the classification model were identified based on the variable influence on projection (VIP) scores (a weighted sum of squares of the PLS loadings taking into account the amount of explained class-variation in each dimension). To visualise differential expressions of metabolites in larvae from the static and flow through systems, the top 12 metabolites (ranked by their t-test statistics) were used to perform HCA (distance $=$ Pearson's correlation; aggregation $=$ Ward's criterion). The constructed dendrogram is codisplayed with the results of heat map analysis to reveal differences in metabolite abundances and assist conception of between-class and between-metabolite clusters. 


\section{Results}

\section{Effect of handling and water exchange}

The effect of handling and water exchange on the metabolic profile of larvae after $1 \mathrm{~h}$ re-acclimatisation is displayed in Table 2 . The majority of detected metabolites before and after the process did not vary significantly. However, succinate decreased $(\mathrm{FC}=-1.93)$, whereas alanine showed a slight increase $(\mathrm{FC}=0.29)$ (paired $t$ tests; $p<0.05)$ (Fig. 1).

Table 2

Metabolic profiles of larvae before (pre-handled) and after (post-handled) a prolonged handling and water exchange process

\begin{tabular}{|c|c|c|c|c|}
\hline \multirow{2}{*}{ Metabolite } & \multicolumn{2}{|c|}{ Mean relative abundance $( \pm \mathrm{SD})$} & \multirow{2}{*}{$\begin{array}{l}\log _{2} \\
\text { FC }\end{array}$} & \multirow{2}{*}{$\begin{array}{l}T \text { test } \\
p \\
\text { value }\end{array}$} \\
\hline & Pre-handled & Post-handled & & \\
\hline Alanine & $1.60^{\mathrm{E}+01} \pm 5.24^{\mathrm{E}-02}$ & $1.95^{\mathrm{E}+01} \pm 4.02^{\mathrm{E}-03}$ & 0.29 & 0.007 \\
\hline Aspartic acid & $2.07^{\mathrm{E}-02} \pm 2.93^{\mathrm{E}-02}$ & $8.55^{\mathrm{E}-02} \pm 1.85^{\mathrm{E}-02}$ & 1.54 & 0.260 \\
\hline Benzoic acid & $4.29^{\mathrm{E}-02} \pm 2.48^{\mathrm{E}-03}$ & $2.55^{\mathrm{E}-02} \pm 2.14^{\mathrm{E}-02}$ & -1.06 & 0.417 \\
\hline Decanoic acid & $1.30^{\mathrm{E}-01} \pm 2.87^{\mathrm{E}-02}$ & $6.41^{\mathrm{E}-02} \pm 3.05^{\mathrm{E}-02}$ & -1.09 & 0.361 \\
\hline Fumarate & $1.06^{\mathrm{E}+01} \pm 3.58^{\mathrm{E}+00}$ & $9.84^{\mathrm{E}+00} \pm 1.05^{\mathrm{E}+00}$ & -0.07 & 0.854 \\
\hline Glycine & $6.25^{\mathrm{E}+01} \pm 3.61^{\mathrm{E}+00}$ & $6.33^{\mathrm{E}+01} \pm 2.11^{\mathrm{E}+00}$ & 0.02 & 0.884 \\
\hline $\begin{array}{l}\text { Heptadecanoic } \\
\text { acid }\end{array}$ & $2.71^{\mathrm{E}-01} \pm 9.62^{\mathrm{E}-02}$ & $1.89^{\mathrm{E}-01} \pm 1.53^{\mathrm{E}-02}$ & -0.48 & 0.487 \\
\hline Hexanoic acid & $1.68^{\mathrm{E}-01} \pm 1.21^{\mathrm{E}-01}$ & $1.79^{\mathrm{E}-01} \pm 1.69^{\mathrm{E}-01}$ & -0.13 & 0.969 \\
\hline Isoleucine & $5.53^{\mathrm{E}-02} \pm 2.15^{\mathrm{E}-02}$ & $6.76^{\mathrm{E}-02} \pm 1.40^{\mathrm{E}-02}$ & 0.33 & 0.261 \\
\hline Itaconic acid & $3.74^{\mathrm{E}-02} \pm 1.67^{\mathrm{E}-02}$ & $2.79^{\mathrm{E}-02} \pm 2.85^{\mathrm{E}-03}$ & -0.35 & 0.509 \\
\hline Lactate & $4.72^{\mathrm{E}-01} \pm 1.19^{\mathrm{E}-01}$ & $2.44^{\mathrm{E}-01} \pm 6.56^{\mathrm{E}-02}$ & -0.96 & 0.331 \\
\hline Leucine & $9.45^{\mathrm{E}-02} \pm 4.29^{\mathrm{E}-03}$ & $1.85^{\mathrm{E}-01} \pm 5.37^{\mathrm{E}-02}$ & 0.94 & 0.234 \\
\hline L-Norvaline & $1.01^{\mathrm{E}+00} \pm 2.53^{\mathrm{E}-01}$ & $2.02^{\mathrm{E}+00} \pm 4.95^{\mathrm{E}-01}$ & 1.00 & 0.307 \\
\hline Myristic acid & $1.27^{\mathrm{E}-01} \pm 5.23^{\mathrm{E}-02}$ & $1.22^{\mathrm{E}-01} \pm 1.45^{\mathrm{E}-02}$ & 0.00 & 0.874 \\
\hline \multicolumn{5}{|c|}{$\begin{array}{l}\text { Positive foldchange (FC) values represent mean metabolite abundances } \\
\text { which were higher in the post-handled samples and negative FC values } \\
\text { represent those that were lower }\end{array}$} \\
\hline
\end{tabular}




\begin{tabular}{|c|c|c|c|c|}
\hline \multirow{2}{*}{ Metabolite } & \multicolumn{2}{|c|}{ Mean relative abundance $( \pm$ SD) } & \multirow{2}{*}{$\begin{array}{l}\log _{2} \\
\text { FC }\end{array}$} & \multirow{2}{*}{$\begin{array}{l}T \text { test } \\
p \\
\text { value }\end{array}$} \\
\hline & Pre-handled & Post-handled & & \\
\hline Nicotinic acid & $8.91^{\mathrm{E}-02} \pm 1.47^{\mathrm{E}-02}$ & $9.04^{\mathrm{E}-02} \pm 8.47^{\mathrm{E}-03}$ & 0.03 & 0.950 \\
\hline $\begin{array}{l}\text { Octadecanoic } \\
\text { acid }\end{array}$ & $8.38^{\mathrm{E}-01} \pm 4.89^{\mathrm{E}-01}$ & $5.62^{\mathrm{E}-01} \pm 1.69^{\mathrm{E}-01}$ & -0.48 & 0.659 \\
\hline Oleic acid & $8.22^{\mathrm{E}-02} \pm 2.95^{\mathrm{E}-02}$ & $6.46^{\mathrm{E}-02} \pm 6.11^{\mathrm{E}-03}$ & -0.30 & 0.481 \\
\hline Oxalic acid & $3.91^{\mathrm{E}-01} \pm 1.91^{\mathrm{E}-01}$ & $2.66^{\mathrm{E}-01} \pm 6.86^{\mathrm{E}-02}$ & -0.49 & 0.620 \\
\hline $\begin{array}{l}\text { Palmitelaidic } \\
\text { acid }\end{array}$ & $3.74^{\mathrm{E}-02} \pm 7.38^{\mathrm{E}-03}$ & $4.69^{\mathrm{E}-02} \pm 4.89^{\mathrm{E}-03}$ & 0.34 & 0.116 \\
\hline Palmitic acid & $5.32^{\mathrm{E}-01} \pm 1.23^{\mathrm{E}-01}$ & $4.12^{\mathrm{E}-01} \pm 5.21^{\mathrm{E}-02}$ & -0.35 & 0.512 \\
\hline $\begin{array}{l}\text { Palmitoleic } \\
\text { acid }\end{array}$ & $3.83^{\mathrm{E}-02} \pm 6.67^{\mathrm{E}-03}$ & $6.23^{\mathrm{E}-02} \pm 7.11^{\mathrm{E}-03}$ & 0.71 & 0.246 \\
\hline $\begin{array}{l}\text { Pentadecanoic } \\
\text { acid }\end{array}$ & $2.49^{\mathrm{E}-02} \pm 1.64^{\mathrm{E}-02}$ & $1.33^{\mathrm{E}-02} \pm 4.96 \mathrm{E}^{-03}$ & -0.77 & 0.586 \\
\hline Phenylalanine & $2.33^{\mathrm{E}-02} \pm 1.82^{\mathrm{E}-03}$ & $3.82^{\mathrm{E}-02} \pm 1.10^{\mathrm{E}-02}$ & 0.69 & 0.259 \\
\hline Proline & $3.30^{\mathrm{E}-01} \pm 1.07^{\mathrm{E}-01}$ & $4.82^{\mathrm{E}-01} \pm 1.68^{\mathrm{E}-03}$ & 0.59 & 0.291 \\
\hline$p$-Toluic acid & $3.80^{\mathrm{E}-01} \pm 2.15^{\mathrm{E}-01}$ & $2.72^{\mathrm{E}-01} \pm 1.18^{\mathrm{E}-01}$ & -0.43 & 0.724 \\
\hline Pyroglutamate & $2.21^{\mathrm{E}-01} \pm 2.13^{\mathrm{E}-02}$ & $2.81^{\mathrm{E}-01} \pm 9.66^{\mathrm{E}-03}$ & 0.35 & 0.221 \\
\hline Succinate & $2.74^{\mathrm{E}+00} \pm 5.59^{\mathrm{E}-01}$ & $7.89^{\mathrm{E}-01} \pm 4.83^{\mathrm{E}-01}$ & -1.93 & 0.018 \\
\hline
\end{tabular}

\section{Fig. 1}

Metabolites that were identified as being statistically different ( $t$ test; $p<0.05$ ) before (pre) and after (post) a prolonged handling and water exchange process (mean $\pm \mathrm{SD}$ ). The primary $y$-axis represents a standardised (autoscaled) data measure which places abundances of different metabolites on the same scale since absolute variations in abundance are not necessarily proportional to the biological relevance of metabolites. The secondary $y$-axis represents foldchange (FC) values which indicates the relative magnitude of difference between the sample groups in the unstandardized data 


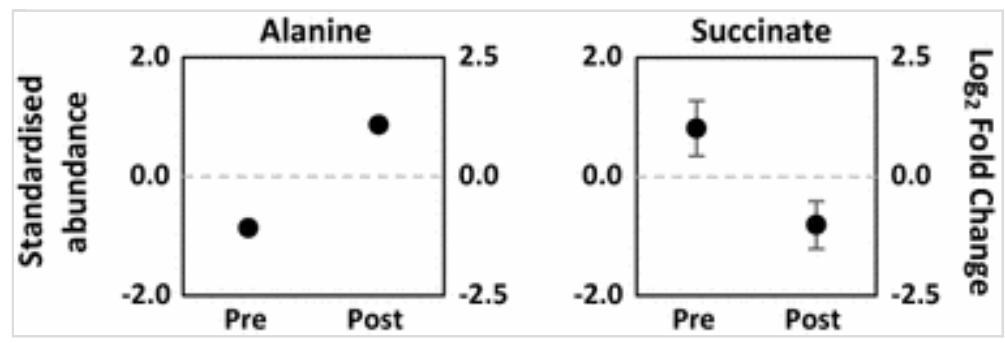

AQ1

\section{Effect of culture system}

The effect of culture system on assigned metabolites is displayed in Table 3 . Univariate analysis identified nine metabolites with significantly altered (unpaired $t$ test; $p<0.05$ ) expression patterns (Fig. 2). HCA analysis of all metabolites showed the intrinsic clustering of samples and revealed two main groupings, which could be attributed to the flow through and static culture systems (Fig. $3 \mathrm{a}$ ). In addition, there was no clear clustering of the static samples before and after the water exchange. PCA analysis revealed that the first two components explained $76.7 \%$ of the variability in the data (Fig. $3 \mathrm{~b}$ ). Furthermore, samples clustered distinctly into their respective treatments with non-overlapping $95 \%$ confidence intervals, which indicated that a good level of class discrimination was possible. The scores along PC1 were primarily responsible for this split and the PC1 loadings (Fig. $3 \mathrm{c}$ ) revealed that variations in numerous metabolites contributed towards the separation. Since an effect of handling and water exchange was not apparent using the unsupervised HCA and PCA methods, these four samples were subsequently re-classified as 'static system samples' for the remaining multivariate analyses.

\section{Table 3}

Metabolic profiles of larvae reared to 10 days post-fertilisation in low-density static and high-density flow through systems

\begin{tabular}{|c|c|c|c|c|}
\hline \multirow{2}{*}{ Metabolite } & \multicolumn{2}{|c|}{ Mean relative abundance $( \pm \mathrm{SD})$} & \multirow{2}{*}{$\begin{array}{l}\log _{2} \\
\text { FC }\end{array}$} & \multirow{2}{*}{$\begin{array}{l}T \text { test } \\
p \\
\text { value }\end{array}$} \\
\hline & Static & Flowthrough & & \\
\hline Alanine & $1.60^{\mathrm{E}+01} \pm 5.24^{\mathrm{E}-02}$ & $1.10^{\mathrm{E}+01} \pm 6.72^{\mathrm{E}-01}$ & -0.69 & 0.004 \\
\hline
\end{tabular}

Positive foldchange (FC) values represent mean metabolite abundances which were higher in the flowthrough system samples and negative FC values represent those that were lower 


\begin{tabular}{|c|c|c|c|c|}
\hline \multirow{2}{*}{ Metabolite } & \multicolumn{2}{|c|}{ Mean relative abundance $( \pm$ SD) } & \multirow{2}{*}{$\begin{array}{l}\log _{2} \\
\text { FC }\end{array}$} & \multirow{2}{*}{$\begin{array}{l}T \text { test } \\
p \\
\text { value }\end{array}$} \\
\hline & Static & Flowthrough & & \\
\hline Aspartic acid & $2.07^{\mathrm{E}-02} \pm 2.93^{\mathrm{E}-02}$ & $2.93^{\mathrm{E}-01} \pm 6.78^{\mathrm{E}-02}$ & 2.33 & 0.014 \\
\hline Benzoic acid & $4.29^{\mathrm{E}-02} \pm 2.48^{\mathrm{E}-03}$ & $1.11^{\mathrm{E}-02} \pm 1.02^{\mathrm{E}-02}$ & -1.62 & 0.068 \\
\hline Decanoic acid & $1.30^{\mathrm{E}-01} \pm 2.87^{\mathrm{E}-02}$ & $5.89^{\mathrm{E}-02} \pm 3.56^{\mathrm{E}-02}$ & -0.72 & 0.267 \\
\hline Fumarate & $1.06^{\mathrm{E}+01} \pm 3.58^{\mathrm{E}+00}$ & $3.26^{\mathrm{E}+00} \pm 2.84^{\mathrm{E}+00}$ & -1.65 & 0.028 \\
\hline Glycine & $6.25^{\mathrm{E}+01} \pm 3.61^{\mathrm{E}+00}$ & $8.16^{\mathrm{E}+01} \pm 3.19^{\mathrm{E}+00}$ & 0.38 & 0.002 \\
\hline $\begin{array}{l}\text { Heptadecanoic } \\
\text { acid }\end{array}$ & $2.71^{\mathrm{E}-01} \pm 9.62^{\mathrm{E}-02}$ & $1.24^{\mathrm{E}-01} \pm 4.35^{\mathrm{E}-03}$ & -0.89 & 0.064 \\
\hline Hexanoic acid & $1.68^{\mathrm{E}-01} \pm 1.21^{\mathrm{E}-01}$ & $4.83^{\mathrm{E}-02} \pm 3.54^{\mathrm{E}-02}$ & -1.84 & 0.126 \\
\hline Isoleucine & $5.53^{\mathrm{E}-02} \pm 2.15^{\mathrm{E}-02}$ & $2.40^{\mathrm{E}-02} \pm 9.41^{\mathrm{E}-03}$ & -1.36 & 0.014 \\
\hline Itaconic acid & $3.74^{\mathrm{E}-02} \pm 1.67^{\mathrm{E}-02}$ & $1.92^{\mathrm{E}-02} \pm 4.20^{\mathrm{E}-03}$ & -0.77 & 0.092 \\
\hline Lactate & $4.72^{\mathrm{E}-01} \pm 1.19^{\mathrm{E}-01}$ & $1.71^{\mathrm{E}-01} \pm 1.89^{\mathrm{E}-02}$ & -1.06 & 0.091 \\
\hline Leucine & $9.45^{\mathrm{E}-02} \pm 4.29^{\mathrm{E}-03}$ & $4.14^{\mathrm{E}-02} \pm 3.14^{\mathrm{E}-02}$ & -1.76 & 0.042 \\
\hline L-Norvaline & $1.01^{\mathrm{E}+00} \pm 2.53^{\mathrm{E}-01}$ & $7.30^{\mathrm{E}-01} \pm 8.91^{\mathrm{E}-02}$ & -1.05 & 0.099 \\
\hline Myristic acid & $1.27^{\mathrm{E}-01} \pm 5.23^{\mathrm{E}-02}$ & $1.02^{\mathrm{E}-01} \pm 1.09^{\mathrm{E}-02}$ & -0.29 & 0.253 \\
\hline Nicotinic acid & $8.91^{\mathrm{E}-02} \pm 1.47^{\mathrm{E}-02}$ & $1.05^{\mathrm{E}-01} \pm 2.35^{\mathrm{E}-02}$ & 0.23 & 0.381 \\
\hline $\begin{array}{l}\text { Octadecanoic } \\
\text { acid }\end{array}$ & $8.38^{\mathrm{E}-01} \pm 4.89^{\mathrm{E}-01}$ & $3.36^{\mathrm{E}-01} \pm 6.15^{\mathrm{E}-02}$ & -1.06 & 0.119 \\
\hline Oleic acid & $8.22^{\mathrm{E}-02} \pm 2.95^{\mathrm{E}-02}$ & $6.51^{\mathrm{E}-02} \pm 1.57^{\mathrm{E}-02}$ & -0.17 & 0.564 \\
\hline Oxalic acid & $3.91^{\mathrm{E}-01} \pm 1.91^{\mathrm{E}-01}$ & $1.80^{\mathrm{E}-01} \pm 1.39^{\mathrm{E}-01}$ & -0.86 & 0.227 \\
\hline $\begin{array}{l}\text { Palmitelaidic } \\
\text { acid }\end{array}$ & $3.74^{\mathrm{E}-02} \pm 7.38^{\mathrm{E}-03}$ & $4.24^{\mathrm{E}-02} \pm 9.81^{\mathrm{E}-03}$ & 0.01 & 0.979 \\
\hline Palmitic acid & $5.32^{\mathrm{E}-01} \pm 1.23^{\mathrm{E}-01}$ & $2.92^{\mathrm{E}-01} \pm 3.35^{\mathrm{E}-02}$ & -0.69 & 0.034 \\
\hline $\begin{array}{l}\text { Palmitoleic } \\
\text { acid }\end{array}$ & $3.83^{\mathrm{E}-02} \pm 6.67^{\mathrm{E}-03}$ & $5.71^{\mathrm{E}-02} \pm 1.05^{\mathrm{E}-02}$ & 0.18 & 0.514 \\
\hline $\begin{array}{l}\text { Pentadecanoic } \\
\text { acid }\end{array}$ & $2.49^{\mathrm{E}-02} \pm 1.64^{\mathrm{E}-02}$ & $3.03^{\mathrm{E}-02} \pm 1.02^{\mathrm{E}-02}$ & 0.66 & 0.244 \\
\hline Phenylalanine & $2.33^{\mathrm{E}-02} \pm 1.82^{\mathrm{E}-03}$ & $2.42^{\mathrm{E}-02} \pm 3.06^{\mathrm{E}-03}$ & -0.35 & 0.317 \\
\hline Proline & $3.30^{\mathrm{E}-01} \pm 1.07^{\mathrm{E}-01}$ & $1.06^{\mathrm{E}-01} \pm 3.82^{\mathrm{E}-02}$ & -1.93 & 0.007 \\
\hline
\end{tabular}

http://eproofing.springer.com/journals/printpage.php?token=aLQkzQX0YGCSGQe85.. 27/08/2015 


\begin{tabular}{|c|c|c|c|c|}
\hline \multirow{2}{*}{ Metabolite } & \multicolumn{2}{|c|}{ Mean relative abundance $( \pm$ SD) } & \multirow{2}{*}{$\begin{array}{l}\log _{2} \\
\text { FC }\end{array}$} & \multirow{2}{*}{$\begin{array}{l}T \text { test } \\
p \\
\text { value }\end{array}$} \\
\hline & Static & Flowthrough & & \\
\hline$p$-Toluic acid & $3.80^{\mathrm{E}-01} \pm 2.15^{\mathrm{E}-01}$ & $1.45^{\mathrm{E}-01} \pm 6.91^{\mathrm{E}-02}$ & -1.17 & 0.101 \\
\hline Pyroglutamate & $2.21^{\mathrm{E}-01} \pm 2.13^{\mathrm{E}-02}$ & $3.47^{\mathrm{E}-01} \pm 3.30^{\mathrm{E}-02}$ & 0.47 & 0.017 \\
\hline Succinate & $2.74^{\mathrm{E}+00} \pm 5.59^{\mathrm{E}-01}$ & $3.10^{\mathrm{E}-01} \pm 3.47^{\mathrm{E}-01}$ & -2.51 & 0.090 \\
\hline \multicolumn{5}{|c|}{$\begin{array}{l}\text { Positive foldchange (FC) values represent mean metabolite abundances } \\
\text { which were higher in the flowthrough system samples and negative FC } \\
\text { values represent those that were lower }\end{array}$} \\
\hline
\end{tabular}

\section{Fig. 2}

Metabolites that were identified as being statistically different ( $t$ test; $p<0.05)$ between the static (S) and flow through (FT) system samples (mean $\pm \mathrm{SD})$. The primary $y$-axis represents a standardised (autoscaled) data measure which places abundances of different metabolites on the same scale since absolute variations in abundance are not necessarily proportional to the biological relevance of metabolites. The secondary $y$-axis represents foldchange (FC) values which indicates the relative magnitude of difference between the sample groups in the unstandardized data 

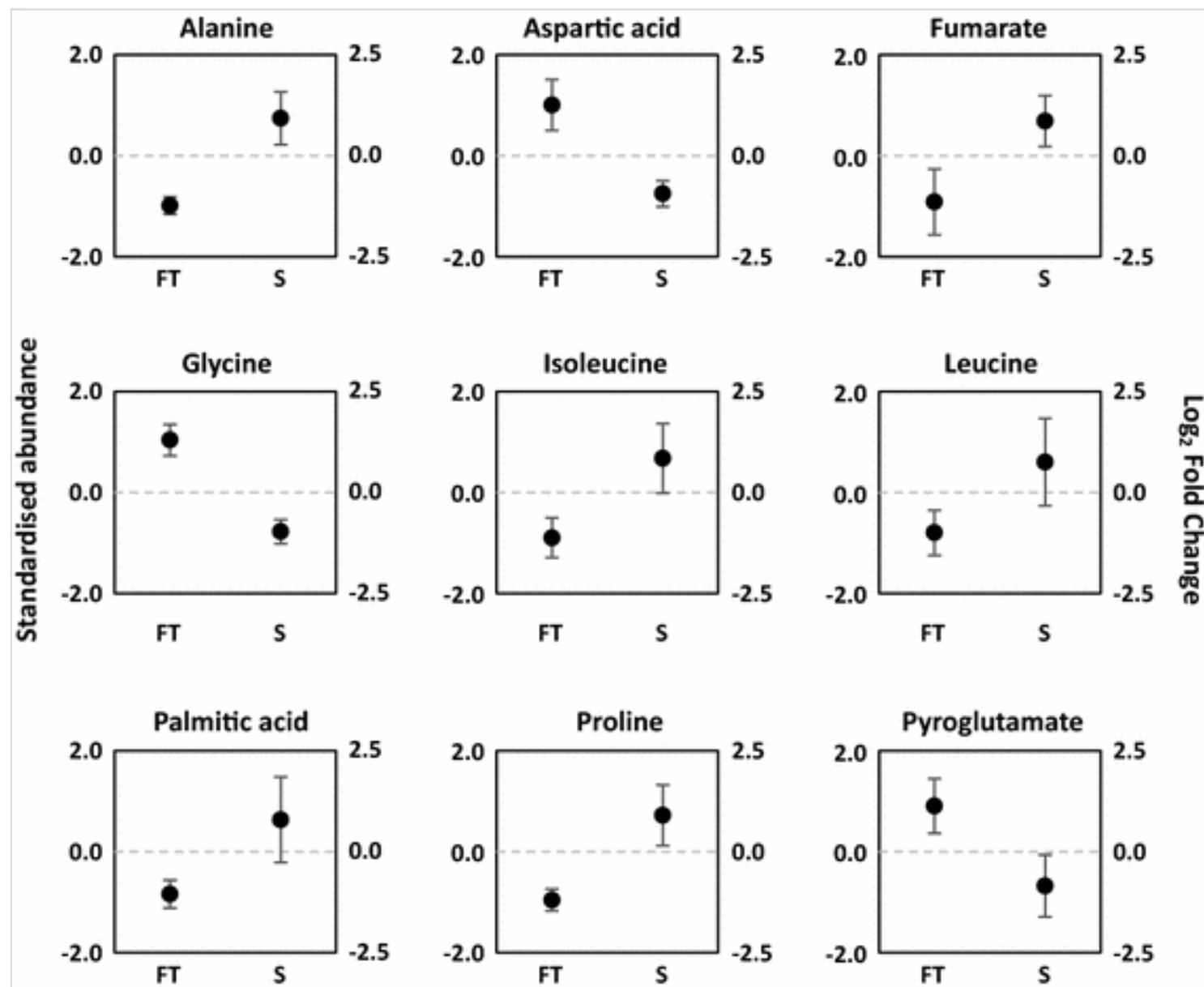

Fig. 3

Multivariate pattern recognition of metabolic profiles in larvae reared under low-density static (S) and high-density flow through (FT) culture systems: a hierarchical cluster analysis of all metabolite data; $\mathbf{b}$ principal component analysis (PCA) 2D score plot of all metabolite data (shaded ellipses represent $95 \%$ confidence intervals); c bar charts of PCA loadings for $\mathrm{PC} 1$ and $\mathrm{PC} 2$; $\mathbf{d}$ projection to latent structures discriminant analysis (PLS-DA) 3D score plot of all metabolite data (shaded ellipsoids are arbitrarily overlaid to enhance visualisation of between-group density clusters); e PLS-DA variable importance in projection (VIP) plot of metabolites which contribute most (VIP $>1.0$ ) towards the PLS-DA classification model. The boxes on the right of the VIP plot represents relative expression of metabolites in the static and flow through systems, where red $=$ high values, and green $=$ lower values 


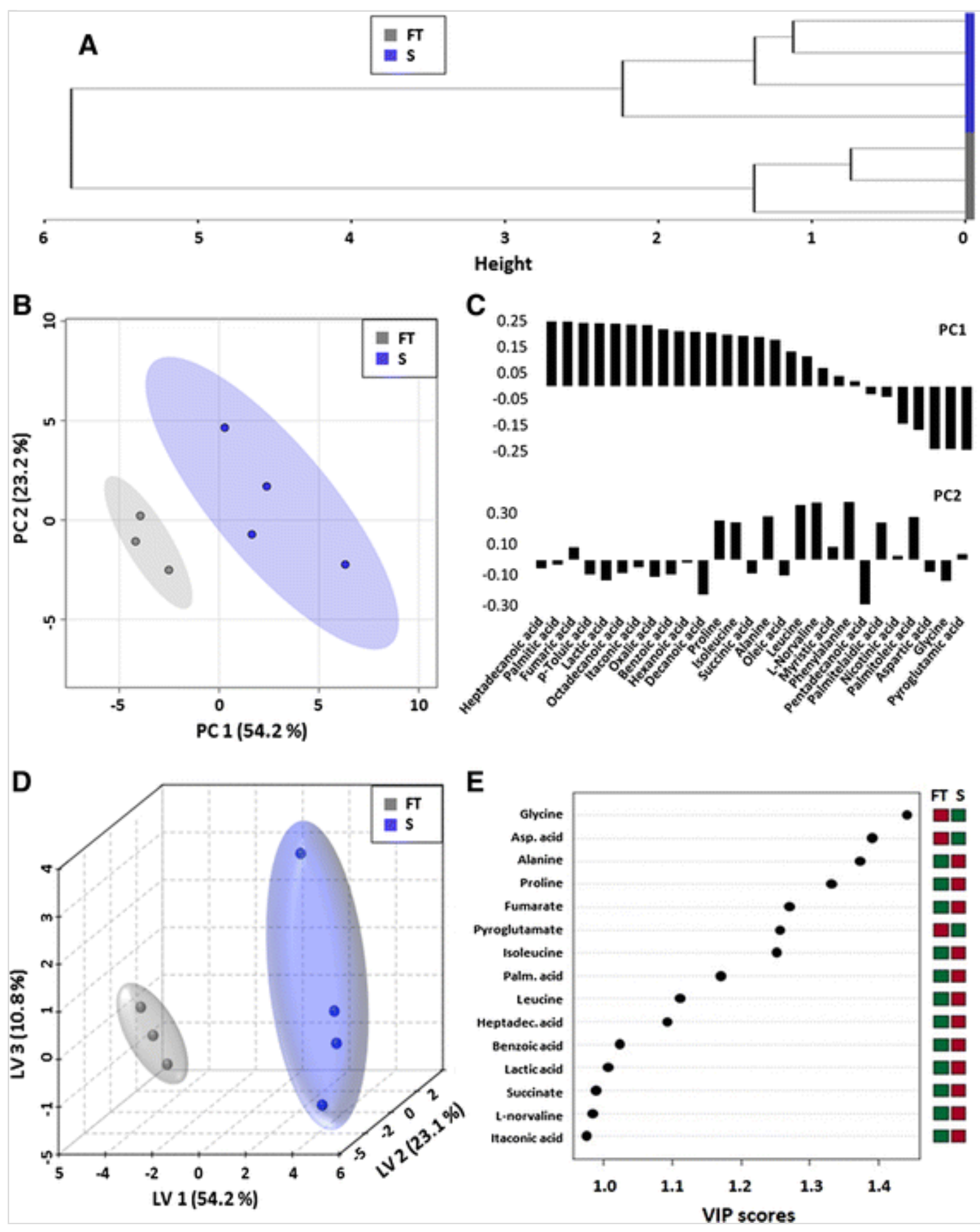

AQ2

PLS-DA analysis was performed to identify and quantitatively rank the main metabolites accountable for the between-class variation. The $3 \mathrm{D}$ score plot revealed that the first three latent variables explained $86.7 \%$ of the variance between the culture systems (Fig. 1d). The performance of the model was evaluated using the first two latent variables and was assessed via LOOCV, which showed a good level of predictive ability $\left(Q^{2}=0.84 ; R^{2}=0.98\right)$. Twelve metabolites with VIP scores $>1.0$ were considered as main features, which contributed towards the 
classification model (Fig. 3e). HCA combined with heatmap analysis was performed to assist visualisation of the twelve metabolites abundances between the culture system classes (Fig. 4). Cluster analysis of the metabolites identified two distinct groups with different expression profiles. Three metabolites generally had higher relative abundances in the flow through system, whereas nine metabolites were lower when compared to the static system.

\section{Fig. 4}

Two-way hierarchical cluster analysis combined with a heatmap to assist visualisation of between-sample and between-metabolite variations. Columns represent samples (grey $=$ flow through, blue $=$ static) and rows represent metabolites. The red/green colour scale represents standardised (autoscaled) abundance data, where red=higher values, and green $=$ lower values

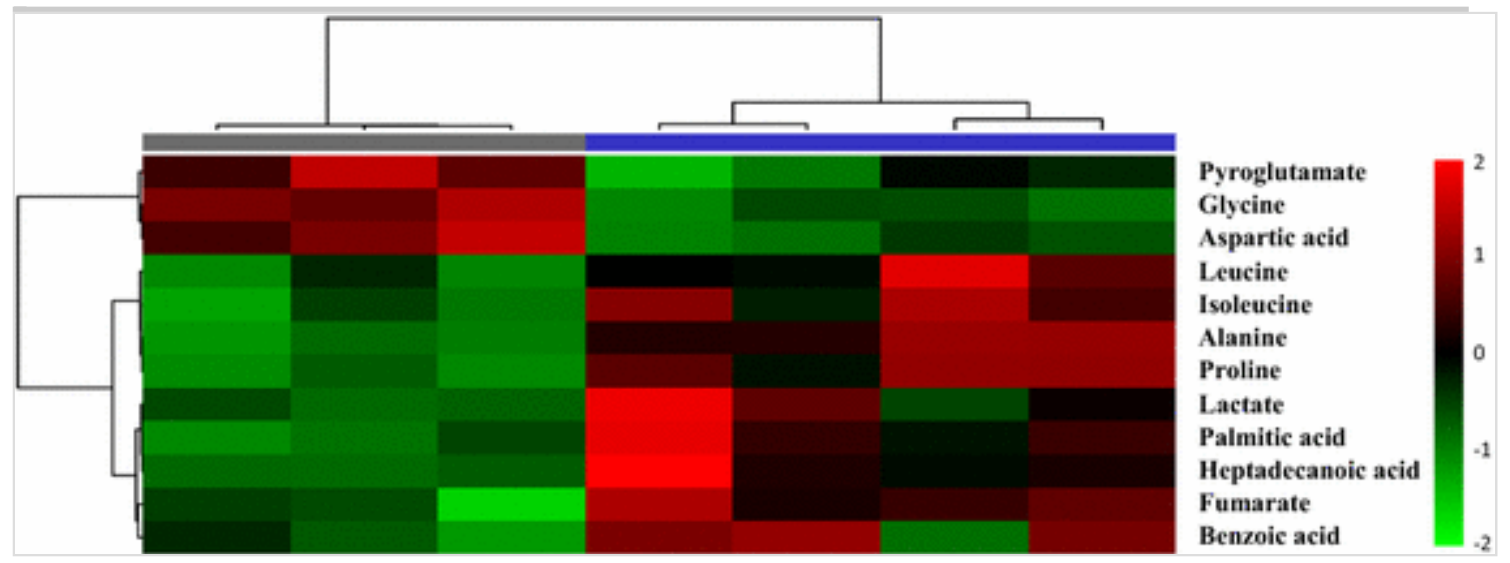

\section{Discussion}

The effect of handling and water exchange on the metabolic profile of larvae resulted in alterations of succinate and alanine. Succinate is a tricarboxylic acid cycle (TCA) intermediate and is capable of donating electrons to the electron transport chain via oxidation to fumarate by succinate dehydrogenase (SDH). Decreased expression of SDH and increased levels of succinate are indicative of oxidative stress in shellfish when oxygen availability is limited (Tuffnail et al. 2009; Anestis et al. 2010; Connor and Gracey 2012), and when organisms are exposed to toxins (Wu et al. 2013a; Hanana et al. 2014) or pathogens (Ji et al. 2013; Wu et al. 2013b). Elevated tissue concentrations of succinate are also indicative of poor larval quality due to lower capacity 
for energy production (Young et al. 2015b). Compared to the beforehandled baseline level, our findings show that succinate levels were lower after the larvae were handled, which suggests increased TCA cycle activity and lack of negative impact on oxidative phosphorylation. AQ3

Alanine is a common osmolyte in marine molluscs (Deaton 2009), and the small increase in this metabolite may indicate a minor shift in osmotic balance after the larvae were screened, exposed to air and placed in fresh seawater. As osmoconformers, shellfish typically accumulate and reduce levels of intracellular osmolytes to maintain cell volume and homeostasis when exposed to higher and lower salinities, respectively. However, concentrations of other principal osmolytes, such as glycine and proline, did not vary after the water exchange. Under substantial osmotic imbalance, concomitant increases or decreases in these metabolites would also be expected (Carregosa et al. 2014; Koyama et al. 2015). These results suggest that the water exchange process has negligible lasting impacts on larval physiology and performance. In addition, subsequent multivariate analyses (HCA and PCA) of all data were supportive of a limited handling effect, since there was no clear treatment-based structure in the samples from the static system.

Conversely, the effect of culture conditions (static vs. flow through) had a more pronounced influence on the metabolic profile of larvae. After 10 days of rearing, mean levels of fumarate and succinate were both lower in the flow through system, which indicates subtle differences in central carbon metabolism, aerobic respiration, and energy production through variations in larval activity and/or nutrient assimilation and conversion. Stocking density is known to affect larval bioenergetics due to changes in animal behaviour (Liu et al. 2006), and may partially explain the variation in TCA cycle intermediates between the different rearing conditions. Free amino acids (FAA's) and free fatty acids (FFA's) were responsible for the majority of other dissimilarities between the flow through and static systems. While FAA's serve osmoregulatory functions in molluscs, they also provide the pool of subunits required for peptide and protein biosynthesis. The FFA profile represents the breakdown products of digested dietary lipids and the 
available building blocks from which newly required lipids can be synthesised. Thus, these variations are indicative of differences in protein and lipid metabolism. Interestingly, growth performance was similar between the static and flow through systems after 10 days of culture. If protein and lipid metabolism were differentially regulated between the two systems, the energetics involved in 'scope for growth' must have been metabolically buffered through an adaptive mechanism. The mechanisms and extent to which mussel larvae can buffer particular metabolic constraints without compromising their developmental timing and growth is unknown, but such knowledge would be highly valuable for the aquaculture industry.

Other metabolites that contributed towards the PLS-DA classification model included benzoic acid and lactate, which, while not statistically different, were both slightly higher in the static system. Fluctuations in endogenous benzoic acid are known to occur in aquatic organisms when exposed to particular pollutants. For example, Spann et al. (2011) recently used a metabolomics-based approach to investigate the effect of sediment contamination on clams (Corbicula fluminea) and found that levels of benzoic acid increased in response to low-level heavy metal exposure. In another metabolic profiling study, Ralston-Hooper et al. (2011) also found similar responses in amphipods (Hyalella azteca) exposed to the widely used agricultural herbicide atrazine. We did not measure potential contaminants in the seawater used in the current study. However, it is possible that the water in the static and flow through systems had different chemical compositions at certain intervals during the culture period since holding ponds are re-filled daily during high tide for continuous flow through use, and $100 \%$ water exchanges in the static system were performed every other day. Lactate in molluscs is an end product of anaerobic respiration and high levels are indicative of respiratory stress (Liu et al. 2014). On the other hand, low levels of lactate in molluscs are indicative of food limitation due to conversion to glucose during gluconeogenesis (Roznere et al. 2014). Although we do not yet have a reference value for lactate production in mussel larvae, the variability within and between each culture system suggests reasonably similar performance in terms of oxygen and food availability, which is in accordance with the employed parameters. 
We previously used a metabolomics-based approach to identify four candidate biomarkers for assessing the quality of hatchery-reared larvae based on intra-cohort variations in growth (Young et al. 2015b). The biomarkers involve metabolite ratios of succinate to alanine, glycine, myristic acid and pyroglutamate. In the current study, analysis of these values showed no significant differences between larvae from the flow through and static systems (Table 4). This finding agrees with the observed shell length data and further substantiates the use of these biomarkers for evaluating proxies for larval quality. The fact that metabolic profiling can be used to successfully detect variable physiological characteristics in hatchery-reared larvae, which have both observable and non-observable morphological traits, highlights the unique value that metabolomics-based approaches can deliver. Our current results demonstrate that the highly sensitive and dynamic larval metabolome can be used to construct classification models which can identify the culture conditions under which the organisms were reared and assist novel hypothesis generation for future studies. In addition, these results also support the continued use of high-density culture practices and indicate that short-term restrictions on the duration of screening are unnecessary. The combination of metabolic profiling with multivariate pattern recognition techniques is a powerful approach, which will undoubtedly be applied more widely in the future of aquaculture-related research to assist optimisation and fine-scale tuning of larviculture parameters.

\section{Table 4}

Statistical analyses of metabolite ratio biomarkers (identified by Young et al. [2015b]) for assessing intra-cohort growth variation as a proxy for larval quality in larvae reared under low-density static and high-density flow through culture systems

\begin{tabular}{|l|l|l|l|}
\hline \multirow{2}{*}{ Candidate biomarker } & \multicolumn{2}{|l|}{$\log _{2}$ ratio \pm SD } & \multirow{2}{*|}{ T test $\boldsymbol{p}$ value } \\
\cline { 2 - 4 } & Flowthrough & Static & \\
\hline Pyroglutamate/succinate & $1.42 \pm 2.82$ & $-2.48 \pm 1.44$ & 0.123 \\
\hline Glycine/succinate & $9.30 \pm 2.95$ & $5.50 \pm 1.27$ & 0.143 \\
\hline Alanine/succinate & $6.41 \pm 2.88$ & $3.67 \pm 1.40$ & 0.235 \\
\hline Myristic acid/succinate & $-0.35 \pm 3.03$ & $-3.52 \pm 1.21$ & 0.205 \\
\hline
\end{tabular}




\section{Acknowledgments}

We are thankful to Rodney Roberts, Dan McCall, Nicola Hawes, Sarah Cumming and Shellfish Production and Technology New Zealand Ltd (SPATnz) for assisting with larval production, and to Margarita Markovskaya for assistance with the sample processing at the Metabolomics Laboratory, University of Auckland. This project was partially funded by a Faculty Research Grant to A. C. Alfaro. We are grateful for the fruitful discussions with the Aquaculture Biotechnology Group, which improved the manuscript.

\section{References}

Aggio R, Villas-Bôas SG, Ruggiero K (2011) Metab: an R package for high-throughput analysis of metabolomics data generated by GCMS. Bioinformatics 27:2316-2318

Alfaro AC, Young T (in review) Showcasing metabolomics in aquaculture: a review. Aquaculture

AQ4

Anestis A, Pörtner HO, Michaelidis B (2010) Anaerobic metabolic patterns related to stress responses in hypoxia exposed mussels Mytilus galloprovincialis. J Exp Mar Biol Ecol 394(1):123-133

Capson TL, Guinotte J (2014) Future proofing New Zealand's shellfish aquaculture: monitoring and adaptation to ocean acidification. New Zealand Aquatic Environment and Biodiversity Report, No. 136, Ministry for Primary Industries. ISBN 978-0-47843763-8

Carrasco AV, Astorga M, Cisterna A, Farías A, Espinoza V, Uriarte I (2014) Pre-feasibility study for the installation of a Chilean mussel Mytilus chilensis (Hupé, 1854) seed hatchery in the Lakes region, Chile. Fish Aquac J 5(3):102. doi:10.4172/2150-3508.1000102 
Carregosa V, Figueira E, Gil AM, Pereira S, Pinto J, Soares AM, Freitas R (2014) Tolerance of Venerupis philippinarum to salinity: osmotic and metabolic aspects. Comp Biochem Physiol A Mol Integr Physiol 171:36-43

Connor KM, Gracey AY (2012) High-resolution analysis of metabolic cycles in the intertidal mussel Mytilus californianus. Am J Physiol-Regul Integr Comp Physiol 302(1):R103-R111

Deaton L (2009) Osmotic and ionic regulation in molluscs. In: Evan DH (ed) Osmotic and ionic regulations: cells and animals. CRC Press, Boca Raton, pp 107-133

Dunphy BJ, Watts E, Ragg NL (2015) Identifying thermally-stressed adult green-lipped mussels (Perna canaliculus Gmelin, 1791) via metabolomic profiling. Am Malacol Bull 33(1):1-9

Hanana H, Simon G, Kervarec N, Cérantola S (2014) Evaluation of toxicological effects induced by tributyltin in clam Ruditapes decussatus using high-resolution magic angle spinning nuclear magnetic resonance spectroscopy: study of metabolic responses in heart tissue and detection of a novel metabolite. Toxicol Rep 1:777 $-786$

Ji C, Wu H, Wei L, Zhao J, Wang Q, Lu H (2013) Responses of Mytilus galloprovincialis to bacterial challenges by metabolomics and proteomics. Fish Shellfish Immunol 35(2):489-498

Ji C, Cao L, Li F (2015) Toxicological evaluation of two pedigrees of clam Ruditapes philippinarum as bioindicators of heavy metal contaminants using metabolomics. Environ Toxicol Pharmacol 39 (2):545-554

Jin Y, Tian LX, Xie SW, Guo DQ, Yang HJ, Liang GY, Liu YJ (2015) Interactions between dietary protein levels, growth performance, feed utilization, gene expression and metabolic products in juvenile grass carp (Ctenopharyngodon idella). Aquaculture 437:75-83 
Kamermans P, Galley T, Boudry P, Fuentes J, Mccombie H, Batista FM, Blanco A, Dominguez L, Cornette F, Pincot L, Beaumont A (2013) Blue mussel hatchery technology in Europe. In Allan G, Burnell G (eds) Advances in aquaculture hatchery technology. Woodhead Publishing series in food science, technology and nutrition, pp 339-373

Karakach TK, Huenupi EC, Soo EC, Walter JA, Afonso LO (2009) $1 \mathrm{H}-\mathrm{NMR}$ and mass spectrometric characterization of the metabolic response of juvenile Atlantic salmon (Salmo salar) to long-term handling stress. Metabolomics 5(1):123-137

Kesarcodi-Watson A, Kaspar H, Lategan MJ, Gibson L (2012a) Performance of single and multi-strain probiotics during hatchery production of Greenshell ${ }^{\mathrm{TM}}$ mussel larvae, Perna canaliculus. Aquaculture 354-355:56-63

Kesarcodi-Watson A, Miner P, Nicolas JL, Robert R (2012b) Protective effect of four potential probiotics against pathogenchallenge of the larvae of three bivalves: pacific oyster (Crassostrea gigas), flat oyster (Ostrea edulis) and scallop (Pecten maximus). Aquaculture 344-349:29-34

Koyama H, Okamoto S, Watanabe N, Hoshino N, Jimbo M, Yasumoto K, Watabe S (2015) Dynamic changes in the accumulation of metabolites in brackish water clam Corbicula japonica associated with alternation of salinity. Comp Biochem Physiol B Biochem Mol Biol 181:59-70

Liu B, Dong B, Tang B, Zhang T, Xiang J (2006) Effect of stocking density on growth, settlement and survival of clam larvae Meretrix meretrix. Aquaculture 258(1):344-349

Liu CC, Shin PKS, Cheung SG (2014) Comparisons of the metabolic responses of two subtidal nassariid gastropods to hypoxia and reoxygenation. Mar Pollut Bull 82(1):109-116 
Martell DJ, Duhaime J, Parsons GJ (2013) Proof of concept of a scalable hatchery system using modular principles to increase production and survival for commercially important Mytilus species. In: Canadian Aquaculture R\&D Review 2013 (p 57). Aquaculture Association of Canada Special Publication 23

Patti GJ, Yanes O, Siuzdak G (2012) Innovation: metabolomics: the apogee of the omics trilogy. Nat Rev Mol Cell Biol 13(4):263-269

Ragg NL, King N, Watts E, Morrish J (2010) Optimising the delivery of the key dietary diatom Chaetoceros calcitrans to intensively cultured Greenshell ${ }^{\mathrm{TM}}$ mussel larvae, Perna canaliculus. Aquaculture 306(1-4):270-280

Ralston-Hooper KJ, Adamec J, Jannash A, Mollenhauer R, OchoaAcuña H, Sepúlveda MS (2011) Use of GC $\times$ GC/TOF-MS and LC/TOF-MS for metabolomic analysis of Hyalella aztecachronically exposed to atrazine and its primary metabolite, desethylatrazine. J Appl Toxicol 31(5):399-410

Roznere I, Watters GT, Wolfe BA, Daly M (2014) Nontargeted metabolomics reveals biochemical pathways altered in response to captivity and food limitation in the freshwater mussel Amblema plicata. Comp Biochem Physiol D Genom Proteom 12:53-60

Schock TB, Duke J, Goodson A, Weldon D, Brunson J, Leffler JW, Bearden DW (2013) Evaluation of Pacific white shrimp (Litopenaeus vannamei) health during a superintensive aquaculture growout using NMR-based metabolomics. PLoS One 8(3):e59521

Scottish Aquaculture Research Forum (SARF) 2014. New approaches to Mussel Seedstock acquisition. Final report, contract reference: SARF096. ISBN: 978-1-907266-62-1

Smart KF, Aggio RB, Van Houtte JR, Villas-Bôas SG (2010) Analytical platform for metabolome analysis of microbial cells using MCF derivatization followed by gas chromatography-mass spectrometry. Nat Protoc 5:1709-1729 
Spann N, Aldridge DC, Griffin JL, Jones OA (2011) Size-dependent effects of low level cadmium and zinc exposure on the metabolome of the Asian clam, Corbicula fluminea. Aquat Toxicol 105(3):589 $-599$

Tuffnail W, Mills GA, Cary P, Greenwood R (2009) An environmental ${ }^{1} \mathrm{H}$ NMR metabolomic study of the exposure of the marine mussel Mytilus edulis to atrazine, lindane, hypoxia and starvation. Metabolomics 5(1):33-43

Villas-Bôas SG, Nielsen J, Smedsgaard J, Hansen MA, RoessnerTunali U (2007) Metabolome analysis: an introduction. Wiley, New Jersey, p 319. ISBN: 978-0-471-74344-6

Villas-Bôas SG, Smart KF, Sivakumaran S, Lane GA (2011) Alkylation or silylation for analysis of amino and non-amino organic acids by GC-MS? Metabolites 1:3-20

Wilson J (2008) Mussel seed supply-are hatcheries part of the solution? Shellfish News 25:16-19

Wu H, Ji C, Wang Q, Liu X, Zhao J, Feng J (2013a) Manila clam Venerupis philippinarum as a biomonitor to metal pollution. Chin $\mathrm{J}$ Oceanol Limnol 31(1):65-74

Wu H, Ji C, Wei L, Zhao J, Lu H (2013b) Proteomic and metabolomic responses in hepatopancreas of Mytilus galloprovincialis challenged by Micrococcus luteus and Vibrio anguillarum. J Proteom 94:54-67

Xia J, Mandal R, Sinelnikov IV, Broadhurst D, Wishart DS (2015) MetaboAnalyst 3.0-making metabolomics more meaningful. Nucl Acids Res 43(W1):W251-W257

Young T, Alfaro AC (in review) A primer for metabolomics research in aquaculture. Aquaculture 
Young T, Alfaro AC, Robertson J (2011) Effect of neuroactive compounds on the settlement of mussel (Perna canaliculus) larvae. Aquaculture 319(1):277-283

Young T, Alfaro AC, Sánchez-Lazo C, Robertson J (2015a) Putative involvement of adrenergic receptors in regulation of mussel (Perna canaliculus) larval settlement. Mar Biol Res (ahead of print): 1-11. doi:10.1080/17451000.2014.979833

Young T, Alfaro AC, Villas-Bôas S (2015b) Identification of candidate biomarkers for quality assessment of hatchery-reared mussel larvae via GC/MS-based metabolomics. NZ J Mar Freshwat Res 49(1):87-95 